in vivo $33: 1425-1430(2019)$

doi:10.21873/invivo.11620

Review

\title{
Pneumococcal Vaccination Strategies Among HIV-infected Adult Patients: A Review of the Literature
}

\author{
ANNA GARMPI ${ }^{1}$, CHRISTOS DAMASKOS ${ }^{2}$, NIKOLAOS GARMPIS ${ }^{2}$, ALEXANDROS PATSOURAS ${ }^{3}$, \\ SPYRIDON SAVVANIS ${ }^{4}$, NIKOLAOS GRAVVANIS ${ }^{5}$ and EVANGELOS DIAMANTIS ${ }^{6}$ \\ ${ }^{1}$ Internal Medicine Department, Laiko General Hospital, Medical School, \\ National and Kapodistrian University of Athens, Athens, Greece; \\ ${ }^{2}$ Second Department of Propedeutic Surgery, Laiko General Hospital, Medical School, \\ National and Kapodistrian University of Athens, Athens, Greece; \\ ${ }^{3}$ Medical School, National and Kapodistrian University of Athens, Athens, Greece; \\ ${ }^{4}$ Department of Internal Medicine, Elpis General Hospital, Athens, Greece; \\ ${ }^{5}$ Health Center Peristeriou, Athens, Greece; \\ ${ }^{6}$ Department of Endocrinology and Diabetes Center, G. Gennimatas General Hospital, Athens, Greece
}

\begin{abstract}
Background/Aim: Streptococcus pneumoniae is the leading cause of bacterial pneumonia and an important cause of invasive disease. Despite the antiretroviral therapies, adults infected with human immunodeficiency virus (HIV) are at particular risk for invasive pneumococcal disease (IPD). The purpose of this study was to report the efficacy of the strategies currently being used in pneumococcal vaccination for HIV-infected adults. Materials and Methods: A literature search was performed through electronic databases, for original articles in English, from years 2000 to 2019. Clinical trials controlled or randomized, and cohort studies were included. Results: While 23-valent pneumococcal polysaccharide vaccine (PPV23) is recommended for immunocompromised patients, it has been reported that it is less suitable for HIV-infected patients. Recent guidelines have added pneumococcal conjugate vaccine $(P C V)$ to the list of recommended vaccines. Conclusion: Further studies are needed to determine the optimal vaccines and intervals for subsequent revaccinations during the lifetime.
\end{abstract}

This article is freely accessible online.

Correspondence to: Dr. Anna Garmpi, MD, Internal Medicine Department, Laiko General Hospital, Medical School, National and Kapodistrian University of Athens, 17 Agiou Thoma Street, Athens, 11527, Greece. Tel: +30 6978310010, e-mail: annagar@ windowslive.com

Key Words: Pneumococcal, vaccine, HIV, adult, review.
Streptococcus pneumoniae is a bacterium with more than 90 known subtypes that colonizes the upper respiratory tract and is a frequent element of the normal flora of the nasopharynx of children (up to $65 \%$ in nursery babies) and to a lesser extent of adults (15\%). It is a major cause of morbidity and mortality in children and adults worldwide. Children less than 5 years of age - mainly infants and toddlers up to 2 years of age, followed by adults over 55-65 years of age.

Pneumococcal disease is caused by either person-toperson transmission mainly by respiratory droplets (sneezing, coughing) or by conversion of simple colonization into infection in conditions of decreased body defenses $e . g$. due to fusion, cold, immunosuppression, smoking etc. It causes both non-invasive infections such as acute otitis media, pneumonia and sinusitis, and serious invasive infections such as septicemia, meningitis and severe pneumonia with bacteremia and/or impotence. In adults, the most common clinical manifestation of pneumococcal infection is pneumonia, which accounts for $36 \%$ of community-acquired pneumonia and $50 \%$ of hospital pneumonia.

Of course, it is common knowledge that lower respiratory tract infections are a major factor in morbidity and mortality. In particular, the case-fatality rate of pneumococcal pneumonia is $5-7 \%$ and may be much higher among elderly persons (1). Only in the USA, the cost of hospitalization is charged to the health budget by \$1.3-2.2 billion a year. Globally, pneumococcal disease accounts for 1.6 million deaths a year, particularly affecting people of older ages. In Europe, the incidence of pneumococcal pneumonia appears to be greater than in the other continents (2). In 2050, the proportion of people aged over 65 in Europe will reach 
$30.3 \%(2000,15.7 \%)$, therefore it is easy to see that prevention of pneumococcal disease is more beneficial than treatment.

The fundamental means of prevention is the preparation and extensive administration of a safe and effective vaccine. The US Centers for Disease Control recommended, since the 80's, using the 23-valent pneumococcal polysaccharide vaccine (PPV23) for immunocompromised subjects. This vaccine contains purified polysaccharide antigens of the pneumococcal capsule and covers the 23 strains responsible for $88 \%$ of cases of bacteremia disease. The development of immunity, including increased opsonization, phagocytosis and microbial killing, is achieved through the activation of B-cells. Because the production of antibodies from this vaccine is independent of Tcell activation, no immune memory is induced, mucosal immunity is not increased, and its repeated administration does not provide a booster effect. Vaccine safety has been proven beyond doubt as its most common side effects include mild and self-limiting local reactions. In contrast to safety, the clinical efficacy of the vaccine has been challenged since several studies have shown that in elderly or immunosuppressed patients, as well as in cohorts, there is insufficient production of antibodies whose functional activity is less than the desired (3-5). Other studies - but not all - have concluded that the gradual decrease in antibody titer 5-10 years after initial vaccination with PPV23 does not return to baseline after repeated administration of the same vaccine (6). Similarly, the results of clinical trials have shown completely contradictory results (7). In some publications, the polysaccharide vaccine appears to provide significant protection against the risk of developing non-bacteremic pneumonia, while in others (mainly migraine) this protection appears to be minimal, if not zero (8, 9). The ability to prevent PPV23 from its bactericidal forms of pneumococcal disease is reported as being measurable in all adults $(63-83 \%)$ but very low in the high risk (0-42\%) (10). It should be noted that a newly published eight-year long epidemiological study from two regions of the United Kingdom showed an increase in incidence of invasive pneumococcal disease despite an improvement in vaccination rates with PPV23 from $49 \%$ to $70 \%$ (11).

However, another very recent prospective study, in more than 27,000 patients over 60 years of age, in its precursor report, claims that PPV23 offers some protection against ischemic stroke and myocardial infarction (12). The exact mechanism that is subject to this protective action is unknown, although various assumptions have been made.

It has also been reported that PPV23 booster causes "hyporesponsiveness". Due to this limitation, PPV23 is less suitable for HIV-infected individuals, mainly for those in advanced stages of immunodeficiency. More recent guidelines have added conjugated polysaccharide vaccine (PCV) to the list of recommended vaccines. The recommendation for the use of PCV among HIV-infected adults was supported by data showing that PCV elicits superior immunologic responses.

The PCV exhibits an almost totally consistent positive correlation. It is well known that coupled vaccines stimulate both B- and T-cells, causing intense immunostimulation and immune memory. Although PCV was introduced as a 7valent only in 2000 , it has dramatically reduced peripheral bacteremic disease and nasal pneumococcal prolapse in children, with unwanted events moving to PPV23 levels.

Its action on the nasal passage resulted in a reduction in transmission and subsequent pneumococcal disease in anesthetized adults. This phenomenon is known as "herd immunity" (13). Equally impressive is the fact that vaccination with $\mathrm{PCV}$ also reduced the incidence of pneumonia, demonstrating the bi-directional relationship between the pneumococcus and the viruses in the pathogenesis of the disease (14).

Despite the fact that the antiretroviral therapy helps reconstitute the immune system and suppress HIV, patients with HIV are still at higher risk for pneumococcal disease in comparison to the general population. Therefore, physicians, based on researches and studies conducted so far, suggest that in order to reduce the risk of pneumococcal disease in adults infected by HIV the PPV23 composed of T-cellindependent antigens could be used (15). However, the results of studies that examine the serological responses to PPV23 are conflicting because of the heterogeneity of study design, execution and subjects enrolled. On the other hand, there is moderate evidence to support the routine use of PPV23 in HIV-infected adults according to observational studies of clinical effectiveness. Furthermore, PCV with conjugation of the capsular polysaccharide to a protein carrier, has been shown to have better results on the immune system than PPV23 and to protect HIV-infected children against pneumococcal disease and HIV-infected adolescents and adults against recurrent invasive pneumococcal disease $(16,17)$. The recent guidelines recommend that HIV-infected patients older than 19 years old receive one dose of 13-valent pneumococcal conjugate vaccine (PCV13) followed by a booster vaccination with PPV23 (15). However, assessment of the efficacy and subsequent widespread acceptance of the PCV13/PPV23 sequential administration prime-boost strategy is dependent on the outcome of clinical trials in the setting of HIV infection which may take several years to complete (18).

The purpose of this article was to provide a review on the efficacy of the strategies currently being used in pneumococcal vaccination for HIV-infected adults.

\section{Materials and Methods}

A research was conducted in electronic databases, for original articles in the English or Greek language, from years 2000 to 2019. 

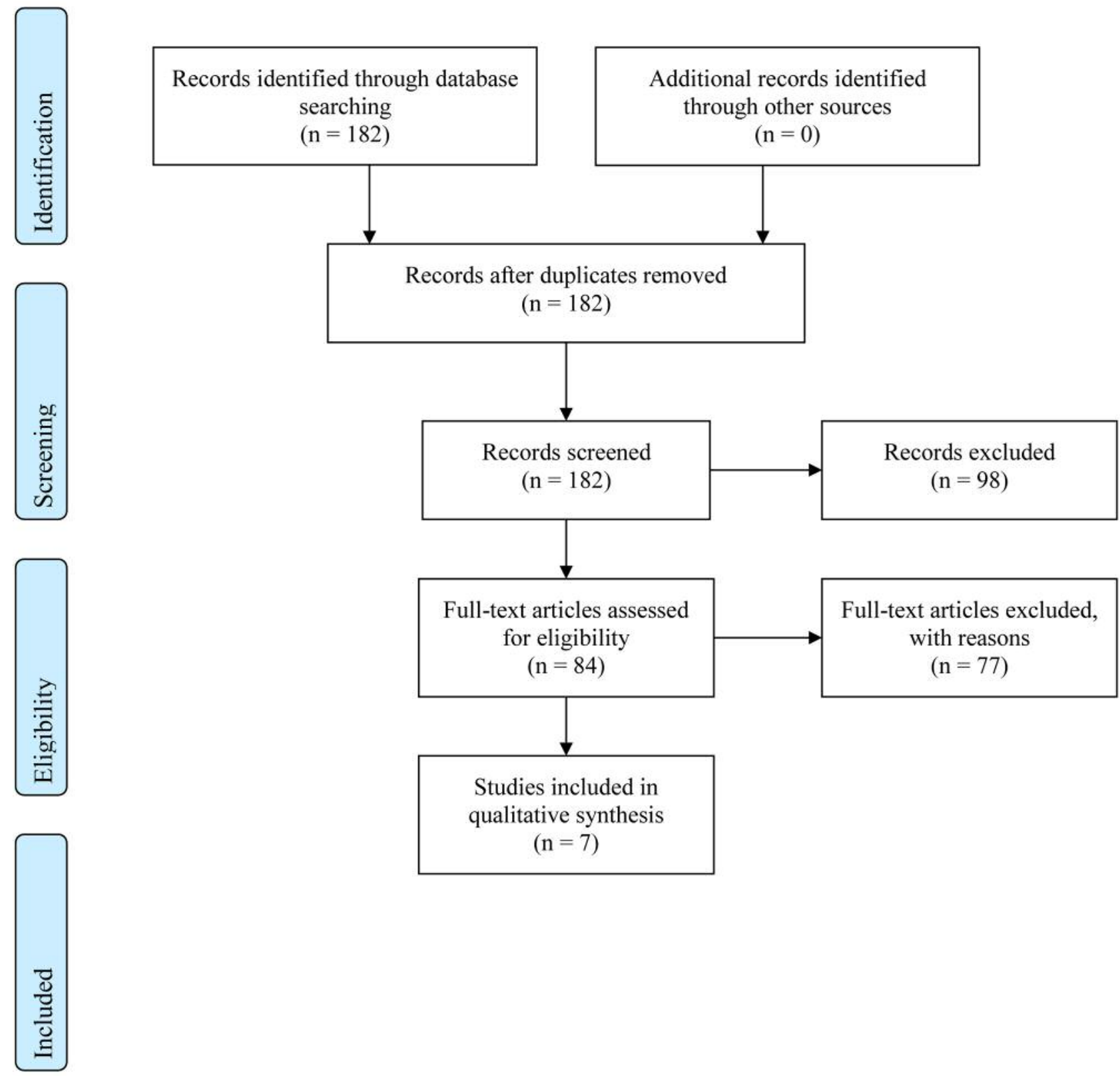

Figure 1. Prisma flow diagram for study identification and selection.

Clinical trials, controlled or randomized, and cohort studies were included.

The following electronic databases were used for the research: PubMed, Scielo, Elsevier, and Google Scholar. After exclusion of duplicated articles, an analysis of the titles of the studies was carried out; those articles that did not address adult HIV patients were excluded. The next step was the analysis of the abstracts of the articles which excluded those that were not related to the review goals. The research method for the articles is illustrated in the Prisma diagram below (Figure 1, Table I).

\section{Results}

French et al. conducted the only clinical efficacy trial on PCV7 in adults and adolescents. They enrolled 496 Malawians $\geq 15$ years old of whom 437 (88\%) were HIVinfected, who had recovered from IPD. The participants received two doses of PCV7, or placebo administered four weeks apart. The researchers where mainly interested in recurrent episodes of IPD caused by vaccine serotypes or 
in vivo $33: 1425-1430(2019)$

Table I. Studies included in the literature review.

\begin{tabular}{|c|c|c|c|c|}
\hline Author & Year & Patients & Study & Results \\
\hline Lu et al. (20) & 2013 & $\begin{array}{l}208 \text { HIV-infected } \\
\text { adults }\end{array}$ & $\begin{array}{c}\text { One dose of PCV7 } \\
\text { or PPV23 }\end{array}$ & $\begin{array}{c}\text { At week } 48 \text {, patients who received PCV demonstrated } \\
\text { a statistically significant higher response rate to } \\
\text { at least } 2 \text { serotypes than those who received PPV } \\
(37.5 \% \text { vs. } 20.2 \%, p=0.006)\end{array}$ \\
\hline Lesprit et al. (21) & 2007 & $\begin{array}{l}212 \text { HIV-infected } \\
\text { adults }\end{array}$ & $\begin{array}{l}\text { Either PCV at week } 0 \\
\text { and PPV at week } \\
4(\mathrm{n}=106) \text { or PPV alone } \\
\text { at week } 4(\mathrm{n}=106)\end{array}$ & $\begin{array}{l}\text { At week } 8 \text {, the profile of response was better in } \\
\text { the prime-boost group compared to the PPV group. } \\
\text { Early differences between groups remained } \\
\text { significant at week } 24 \text { (proportional } \\
\text { OR=2.14; } 95 \% \mathrm{CI}=1.30-3.54 ; p=0.003) \text {. }\end{array}$ \\
\hline Feikin et al. (22) & 2001 & $\begin{array}{l}67 \text { HIV-infected } \\
\text { adults }\end{array}$ & $\begin{array}{l}2 \text { doses of vaccines } \\
\text { and/or placebo } \\
\text { (PCV7-PCV7, PCV7- } \\
\text { PPV23, placebo-PPV23 } \\
\text { and placebo-placebo } \\
\text { groups) given at } \\
\text { an 8-week interval }\end{array}$ & $\begin{array}{l}\text { Patients receiving conjugate-conjugate and } \\
\text { conjugate-polysaccharide had higher antibody } \\
\text { concentrations (serotypes } 4,6 \mathrm{~B}, 9 \mathrm{~V} \text { and serotype } \\
23 \mathrm{~F} \text {, respectively) and opsonophagocytic titers } \\
\text { (functional antibody assay, serotypes } 9 \mathrm{~V}, 23 \mathrm{~F} \\
\text { and serotypes } 4,6 \mathrm{~B}, 9 \mathrm{~V} \text {, respectively) } \\
\text { after the second dose }(p<0.05) \text {. }\end{array}$ \\
\hline Ho et al. (23) & 2013 & $\begin{array}{l}331 \text { HIV-infected } \\
\text { adults }\end{array}$ & $\begin{array}{l}2 \text { doses of PCV7, PPV23 } \\
\text { or placebo given } 60 \text { days } \\
\text { apart (PPV23-placebo, } \\
\text { PCV7-placebo, } \\
\text { PCV7-PPV23) }\end{array}$ & $\begin{array}{l}\text { A greater proportion of PCV7 recipients reached } \\
\text { and sustained IgG antibody concentrations } \\
\text { at least four times as high as those at baseline, } \\
\text { for serotypes } 6 \mathrm{~B} \text { and } 9 \mathrm{~V} \text {. A PPV23 dose after } \\
\text { PCV7 did not enhance immunogenicity. }\end{array}$ \\
\hline Penaranda et al. (24) & 2010 & $\begin{array}{l}202 \text { HIV-infected } \\
\text { adults }\end{array}$ & $\begin{array}{l}\text { PCV and PPV } 4 \text { weeks } \\
\text { after vs. PPV alone. }\end{array}$ & $\begin{array}{l}\text { There were no differences in the two strategies, either } \\
\text { in the percentage of IgG two-fold increase for the } \\
\text { PCV included serotypes or IgG two-fold increase, } \\
\text { reaching the level of } 1 \mathrm{mg} / \mathrm{ml} \text { except for serotype } 23 \mathrm{~F} \\
\text { (26\% responded after PCV and PPV vs. } 14 \% \text { after PPV). }\end{array}$ \\
\hline Marcus et al. (25) & 2016 & $\begin{array}{l}13,079 \text { HIV-infected } \\
\quad \text { and } 137,643 \\
\text { HIV-uninfected adults }\end{array}$ & PPV23 & $\begin{array}{l}\text { PPV23 was not significantly associated with a reduced } \\
\text { risk of IPD among HIV-infected or HIV-uninfected } \\
\text { patients, with a high prevalence of PPV23-covered } \\
\text { serotypes among HIV-infected IPD cases. Both } \\
\text { HIV-uninfected and HIV-infected patients may have } \\
\text { benefited indirectly from PCV7 and PCV13 among } \\
\text { children, licensed in } 2000 \text { and 2010, respectively. }\end{array}$ \\
\hline Sogaard et al. (26) & 2010 & $\begin{array}{l}99 \text { HIV-positive } \\
\text { patients }\end{array}$ & $\begin{array}{l}\text { Double doses of } \\
\text { PCV7 at } 0 \text { and } 3 \text { months } \\
\text { and } 1 \text { dose of PPV23 } \\
\text { at } 9 \text { months, with } \\
\text { experimental patients } \\
\text { receiving } 1 \mathrm{mg} \text { of CPG } \\
7909 \text { added to each of } \\
\text { their } 3 \text { vaccine doses }\end{array}$ & $\begin{array}{l}\text { The proportion of vaccine high responders was higher } \\
\text { in the experimental group }(\mathrm{n}=48) \text { than among controls } \\
(\mathrm{n}=49 ; 48.8 \% \text { vs. } 25.0 \% ; p=0.02) \text { at } 9 \text { months. } \\
\text { Greater proportions of high responders were also } \\
\text { observed at } 3(51.1 \% \text { vs. } 39.6 \% ; p=0.26) \\
4(77.3 \% \text { vs. } 56.3 \% ; p=0.03) \text {, and } \\
10 \text { months }(87.8 \% \text { vs. } 51.1 \% ; p<0.001)\end{array}$ \\
\hline
\end{tabular}

HIV: Human immunodeficiency virus; PCV7: 7-valent pneumococcal conjugate vaccine; PPV23: 23-valent pneumococcal polysaccharide vaccine; PCV: pneumococcal conjugate vaccine; PPV: pneumococcal polysaccharide vaccine; PCV13: 13-valent pneumococcal conjugate vaccine.

serotype 6A. The follow-up of 1.2 years (on average) showed 67 episodes of IPD in 52 HIV-infected patients. Those episodes occurred mainly in the subgroup of participants with CD4 count $<200$ cells/ml at base-line. In HIV-infected patients, the vaccine efficacy was $85 \%$ in the first-year post-vaccination, decreased to $74 \%$ at the followup and dropped down to $25 \%$ thereafter. Moreover, patients with a CD4 count $<200$ cells/ml at baseline had 7.1 -fold greater risk for developing recurrent IPD than those with a CD 4 count $>500$ cells $/ \mathrm{ml}$. In the study of French et al., only
$50 \%$ of the episodes of IPD in the placebo group were attributed to Streprococcus pneumoniae of vaccine serotypes and serotype $6 \mathrm{~A}$. In addition, only $13 \%$ of HIV-infected participants were receiving combination antiretroviral therapy (cART) at baseline. The conclusion was that, in order to protect, at the maximum, adolescents and adults infected by HIV against IPD, PCVs with broader serotype coverage such as PCV13 and early initiation of cART should be the first choice (19). Overall, 208 HIV-infected adults participated in the case-control study by Lu et al. and they 
received either one dose of PCV7 or PPV23, and were matched by CD4 count and plasma HIV RNA load at vaccination. The results showed that significantly higher immune responses to one or two of the four serotypes assessed were maintained by patients who received PCV7 in comparison to those who received PPV23 at both 24 and 48 weeks after vaccination (20).

In the randomized controlled trial by Lesprit et al., 212 HIV-infected adults took part and they received either PCV7 followed by PPV23 4 weeks later (prime-boost group) or PPV23 alone at week 4. Results showed that at week 8, the prime-boost group had higher immune responses, compared to the PPV23 group, and these results remained even until 24 weeks after the first vaccine dose (21).

In the randomized trial by Feikin et al., $67 \mathrm{HIV}$-infected adults were enrolled, and they received two doses of vaccines and/or placebo given at an 8-week interval. Higher antibody concentrations and OPA titers occurred to those receiving PCV7-PCV7 and PCV7-PPV23 in comparison to those receiving placebo-PPV23 at 8 weeks after the second vaccine dose. However, the immune responses were not further increased with booster vaccination with either PCV7 or PPV23 following the first PCV7 dose (22).

Similar findings have been reported in a recent trial by Ho et al. A total of $331 \mathrm{HIV}$-infected adults participated in this study receiving two doses of PCV7, PPV23 or placebo given 60 days apart. Better immune responses were observed in patients receiving primary vaccination with PCV7 compared to those with PPV23 (in two of the three serotypes assessed) at both 60 and 180 days. However, the PCV-placebo and PCVPPV23 groups showed no differences between them (23).

No significant difference in the immune responses between the two groups was also observed in the randomized trial by Penaranda et al. In this trial, $202 \mathrm{HIV}$-infected adults received either one dose of PCV7 followed by PPV23 four weeks later or one dose of PPV23 alone (24). Marcus et al. conducted a cohort study comparing adults infected by HIV to demographically matched HIV-uninfected adults. According to their results, there was no association of the 23 -valent pneumococcal polysaccharide vaccination to a reduced risk of IPD in both groups (25).

Finally, Sogaard et al., evaluated the addition of an adjuvant CPG 7909, a toll-like receptor agonist, in order to improve the immunogenicity of pneumococcal vaccines in the HIV-infected adults. Participants of the study received double doses of PCV7 twice at 0 and 3 months and one dose of PPV23 at 9 months, along with $1 \mathrm{mg}$ of CPG 7909 added to each of the 3 vaccine doses. There were more high vaccine responders in the CPG 7909 group than in the placebo group at 4-, 9- and 10-months post-vaccination and the OPA titers were also higher. In contrast, the study found that adding CPG 7909 to PPV23 did not enhance the antibody response to non-PCV7 serotypes (26).

\section{Conclusion}

The introduction of PCVs with a broader serotype coverage and widespread, early initiation of cART, resulted in an evolution of strategies for preventing pneumococcal pneumonia or IPD in the HIV-infected adults. The guidelines have replaced PPV23 in primary vaccination with PCV13, followed 8 weeks later by revaccination with PPV23. However, the immunogenicity studies of PCV7 vaccination in HIV-infected individuals have a follow-up duration of at most 12 months and thus we cannot have conclusive observations about the sustainability of the immune responses. Further studies should be conducted in order to determine the durability of immune responses to the recommended prime-boost strategy with PCV13 followed by PPV23 and the optimal vaccines and intervals for subsequent revaccinations during the lifetime.

\section{Conflicts of Interest}

The Authors declare that there is no conflict of interest regarding this study.

\section{Authors' Contributions}

ED designed the study and wrote the article. AG, CD, NG and AP collected the data. AG, CD, NG, AP and SS offered scientific advice. $\mathrm{AG}, \mathrm{CD}, \mathrm{NG}$ and $\mathrm{NG}$ revised the article.

\section{References}

1 Hamborsky J, Kroger A and Wolfe S: Pneumococcal disease. In: Epidemiology and prevention of vaccine-preventable diseases. 13th Edition. Hamborsky J, Kroger A and Wolfe S (eds.). Washington, D.C. Public Health Foundation, pp. 279-294, 2015.

2 Brown JS: Geography and the aetiology of community-acquired pneumonia. Respirology 14(8): 1068-1071, 2009. PMID: 199094 56. DOI: 10.1111/j.1440-1843.2009.01641.x

3 Musher DM, Luchi MJ, Watson DA, Hamilton R and Baughn RE: Pneumococcal polysaccharide vaccine in young adults and older bronchitis: determination of IgG responses by ELISA and the effect of adsorption of serum with non-type-specific cell wall polysaccharide. J Infect Dis 161(4): 728-735, 1990. PMID: 2319166. DOI: $10.1093 /$ infdis/161.4.728

4 Schenkein JG, Nahm MH and Dransfield MT: Pneumococcal vaccination for patients with COPD: current practice and future directions. Chest 133(3): 767-774, 2008. PMID: 17890468. DOI: 10.1378/chest.07-0996

5 Rodriguez-Barradas MC, Groover JE, Lacke CE, Gump DW, Lahart CJ, Pandey JP and Musher DM: IgG antibody to pneumococcal capsular polysaccharide in human immunodeficiency virus-infected subjects: persistence of antibody in responders, revaccination in nonresponders, and relationship of immunoglobulin allotype to response. J Infect Dis 173(6): 13471353, 1996. PMID: 8648206. DOI: 10.1093/infdis/173.6.1347

6 Musher DM, Manof SB, Liss C, McFetridge RD, Marchese RD, Bushnell B, Alvarez F, Painter C, Blum MD and Silber JL: 
Safety and antibody response, including antibody persistence for 5 years, after primary vaccination or revaccination with pneumococcal polysaccharide vaccine in middle-aged and older adults. J Infect Dis 201(4): 516-524, 2010. PMID: 20092407. DOI: $10.1086 / 649839$

7 Huang L, Wang L, Li H, Hu Y, Ru W, Han W, Shi G, Ye Q, Han Z, Xia J, Xia S, Xu M and Li J: A phase III clinical trial to evaluate the safety and immunogenicity of 23-valent pneumococcal polysaccharide vaccine (PPV23) in healthy children, adults, and elderly. Hum Vaccin Immunother 15(1): 249-255, 2019. PMID: 30215583. DOI: 10.1080/21645515.2018.1509648

8 Pitsiou GG and Kioumis IP: Pneumococcal vaccination in adults: does it really work? Resp Med 105(12): 1776-1783, 2011. PMID: 21816596. DOI: 10.1016/j.rmed.2011.07.008

9 Maruyama T, Taguchi O, Niederman MS, Morser J, Kobayashi $\mathrm{H}$, Kobayashi T, D'Alessandro-Gabazza C, Nakayama S, Nishikubo K, Noguchi T, Takei Y and Gabazza EC: Efficacy of 23-valent pneumococcal vaccine in preventing pneumonia and improving survival in nursing home residents: double blind, randomized and placebo controlled trial. BMJ 340: c1004, 2010. PMID: 20211953. DOI: 10.1136/bmj.c1004

10 Huss A, Scott P, Stuck A, Trotter C and Egger M: Efficacy of pneumococcal vaccination in adults: a meta-analysis. CMAJ 180(1): 48-58, 2009. PMID: 19124790. DOI: 10.1503/cmaj.080734

11 Gaillat J: Should patients with chronic obstructive pulmonary disease be vaccinated against pneumococcal diseases? Exp Rev Resp Med 3(6): 585-596, 2009. PMID: 20477349. DOI: 10.1586/ers.09.53

12 Elston JW, Santaniello-Newton A, Meigh JA, Harmer D, Allgar V, Allison T, Richardson G, Meigh R, Palmer SR and Barlow G: Increasing incidence of invasive pneumococcal disease and pneumonia despite improved vaccination uptake: surveillance in Hull and East Yorkshire, UK, 2002-2009. Epidemiol Infect 140(7): 1252-1266, 2012. PMID: 22040368. DOI: 10.1017/ S0950268811001907

13 Vila-Corcoles A, Ochoa-Gondar O, Rodringuez-Blanco T, Gutierrez-Perez A, Vila-Rovira A, Gomez F, Raga X, de Diego C, Satue E, Salsench E and EPIVAC Study Group: Clinical effectiveness of pneumococcal vaccination against acute myocardial infarction and stroke in people over 60 years: the CARAMIS study, one-year follow-up. BMC Public Health 12: 222, 2012. PMID: 22436146. DOI: 10.1186/1471-2458-12-222

14 Pletz MW, Maus U, Hohlfeld JM, Lode H and Welte T: Pneumococcal vaccination: conjugated vaccine induces herd immunity and reduces antibiotic resistance. Dtsch Med Wochenschr 133(8): 358-362, 2008. PMID: 18270917. DOI: $10.1055 / \mathrm{s}-2008-1046719$

15 Lee KY, Tsai MS, Kuo KC, Tsai JC, Sun HY, Cheng AC, Chang SY, Lee $\mathrm{CH}$ and Hung CC: Pneumococcal vaccination among HIV-infected adult patients in the era of combination antiretroviral therapy. Hum Vaccin Immunother 10(12): 37003710, 2014. PMID: 25483681. DOI: 10.4161/hv.32247

16 Nunes MC and Madhi SA: Safety, immunogenicity and efficacy of pneumococcal conjugate vaccine in HIV-infected individuals. Hum Vaccin Immunother 8(2): 161-173, 2012. PMID: 22426 374. DOI: $10.4161 / \mathrm{hv} .18432$

17 Cordonnier C, Averbuch D, Maury S and Engelhard D: Pneumococcal immunization in immunocompromised hosts: where do we stand? Expert Rev Vaccines 13(1): 59-74, 2014. PMID: 24308578. DOI: 10.1586/14760584.2014.859990
18 Feldman C, Anderson R and Rossouw T: HIV-related pneumococcal disease prevention in adults. Expert Rev Respir Med 11(3): 181-199, 2017. PMID: 28228053. DOI: 10.1080/ 174763 48.2017.1289841

19 French N, Gordon SB, Mwalukomo T, White SA, Mwafulirwa G, Longwe H, Mwaiponya M, Zijlstra EE, Molyneux ME and Gilks CF: A trial of a 7-valent pneumococcal conjugate vaccine in HIV-infected adults. N Engl J Med 362(9): 812-822, 2010. PMID: 20200385. DOI: 10.1056/NEJMoa0903029

$20 \mathrm{Lu}$ CL, Hung CC, Chuang YC, Liu WC, Su CT, Su YC, Chang SF, Chang SY and Chang SC: Serologic response to primary vaccination with 7 -valent pneumococcal conjugate vaccine is better than with 23 -valent pneumococcal polysaccharide vaccine in HIV-infected patients in the era of combination antiretroviral therapy. Hum Vaccin Immunother 9(2): 398-404, 2013. PMID: 23291936. DOI: $10.4161 /$ hv.22836

21 Lesprit P, Pédrono G, Molina JM, Goujard C, Girard PM, Sarrazin N, Katlama C, Yéni P, Morineau P, Delfraissy JF, Chêne G, Lévy Y and ANRS 114-Pneumovac Study Group: Immunological efficacy of a prime-boost pneumococcal vaccination in HIV-infected adults. AIDS 21(18): 2425-2434, 2007. PMID: 18025879. DOI: 10.1097/QAD.0b013e3282887e91

22 Feikin DR, Elie CM, Goetz MB, Lennox JL, Carlone GM, Romero-Steiner S, Holder PF, O'Brien WA, Whitney CG, Butler JC and Breiman RF: Randomized trial of the quantitative and functional antibody responses to a 7-valent pneumococcal conjugate vaccine and/or 23-valent polysaccharide vaccine among HIV-infected adults. Vaccine 20(3-4): 545-553, 2001. PMID: 11672921.

23 Ho YL, Brandao AP, de Cunto Brandileone MC and Lopes MH: Immunogenicity and safety of pneumococcal conjugate polysaccharide and free polysaccharide vaccines alone or combined in HIV-infected adults in Brazil. Vaccine 31(37): 4047-4053, 2013. PMID: 23684823. DOI: 10.1016/j.vaccine. 2013.04.065

24 Penaranda M, Payeras A, Cambra A, Mila J, Riera M and Majorcan Pneumococcal Study Group: Conjugate and polysaccharide pneumococcal vaccines do not improve initial response of the polysaccharide vaccine in HIV-infected adults. AIDS 24(8): 1226-1228, 2010. PMID: 20299956. DOI: 10.1097/ QAD.0b013e3283389de5

25 Marcus JL, Baxter R, Leyden WA, Muthulingam D, Yee A, Horberg MA, Klein DB, Towner WJ, Chao CR, Quesenberry CP $\mathrm{Jr}$ and Silverberg MJ: Invasive pneumococcal disease among HIV-infected and HIV-uninfected adults in a large integrated healthcare system. AIDS Patient Care STDS 30(10): 463-470, 2016. PMID: 27749111. DOI: 10.1089/apc.2016.0165

26 Sogaard OS, Lohse N, Harboe ZB, Offersen R, Bukh AR, Davis $\mathrm{HL}$, Schonheyder $\mathrm{HC}$ and Ostergaard L: Improving the immunogenicity of pneumococcal conjugate vaccine in HIVinfected adults with a toll-like receptor 9 agonist adjuvant: a randomized, controlled trial. Clin Infect Dis 51(1): 42-50, 2010. PMID: 20504165. DOI: 10.1086/653112 